\title{
Influências da Psicanálise sobre a Psiquiatria
}

\section{Edilnete Sampaio de Siqueira**}

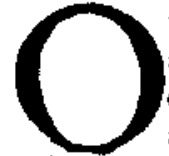
trabalho de supervisão do atendimento ambulatorial em psiquiatria (setor de adultos) do Hospital das Clínicas da Universidade Federal de Pernambuco, tem servido de ponto de partida para uma série de refiexōes e questionamentos sobre qual a possibilidade de utilizarmos alguns conceitos psicanalíticos na prática psiquiátrica.

Utilizando as noções da teoria psicanalítica como respaldo teórico, vimos tentando há quase 10 anos estabelecer um modo de atendimento ambulatorial, no serviço de Psiquiatria do HC (3). Conscientes das inúmeras dificuldades existentes numa grande instituição, nossa luta vem sendo a de tentar passar a idéia de um atendimento em que prevaleça a seriedade e o respeito para com o paciente. Nosso sistema de saúde apresenta falhas em sua prática assistencial, cujas razōes não pretendemos, porém, abordar agora. São freqüentes as longas filas de espera para os atendimentos médicos, como tampouco existe qualquer preocupação em fixar um terapeuta para um mesmo cliente.

Sabemos o quanto é significativo a estruturação do "setting" terapêutico: o enquadramento das sessōes, com horário e freqũêncja fixa, facilita a manifestação da transferência, elemento fundamental para o desenvolvimento de um trabalho posterior.

Dentre as implicações de um momento transferencial, poderíamos destacar como de grande relevância: as expectativas do doente quanto ao terapeuta que 0 atenderá; as fantasias que se instalam acerca da sua doença.

* - Psicanalista do Círculo Psicanalítico de Pernambuco e Psicóloga do Departamento de Neuropsiquiatria do Centro de Ciências da Saúde da Universidade Federal de Pernambuco.

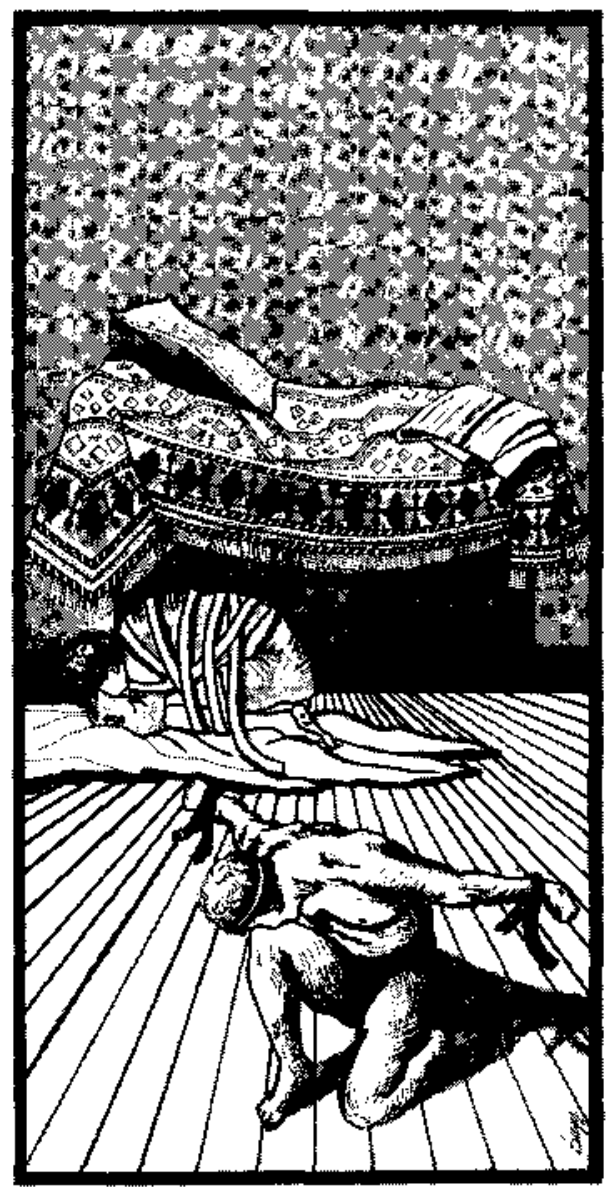

Fantasias, desejos fundamentalmente importantes para que se estabeleça qualquer possibilidade de tratamento. Neste contexto transferencial, também é da máxima importância a pessoa do terapeuta que ali está com suas ansiedades, seus receios e suas dificuldades ante o paciente. Nunca é demais relembrar que ao escutar a história dolorosa e conflitante do seu cliente, o terapeuta não se dá conta do quanto os seus afetos são mobilizados, despertando os núcleos conflitivos, os quais, sem um trabalho tera-

1* . Participação na mesa-redonda sobre Influências da Psicanálise sobre a Psiquiatria, da Jornada de Psiguiatria promovida pela Sociedade de Psiquiatria de Pernambuco, de 2 a 4 de setembro de 1988 , em Recife. pêutico anterior, serão projetados em dificuldades com o paciente, ocasionando um entrelaçamento de emo. ções que impossibilitará uma escuta mais pura e uma atuação mais neutra, para que a história do paciente seja colocada em primeiro lugar.

Refletindo sobre alguns destes itens, nosso trabalho vem consistindo em estabelecer um atendimento no qual os pacientes tenham o enquadramento fixado (dia, freqüência e duração das entrevistas), sendo sempre recebidos pelo mesmo terapeuta. É um mínimo de esforço que podemos fazer para estabelecer um "setting" estruturante, que possibilite um prosseguimento favorável às possibilidades terapêuticas. $O$ terapeuta é orientado, nesse nosso trabalho de supervisão, a escutar o que é dito e o que näo é dito pelos seus clientes; a evitar tanto quanto possível um questionamento minucioso. Conhecendo a importância da escuta analítica, do valor inegável das associaçōes livres tão destacadas por Freud, por que não ficarmos mais atentos ao relato espontâneo do cliente, sem crivá-lo de perguntas tipo interrogatório que, na maioria das vezes, são estéreis e que servem tão somente para preencher o espaço do silêncio, às vezes angustiante para o terapeuta, do que mesmo necessárias para o preenchimento de uma anamnese? Claro que os dados informativos são necessários. Mas, para que a urgência, a necessidade ansiosa de tudo saber de imediato, acabar a consulta e logo se livrar do paciente? $O$ que se esconde atrás dessa dificuldade de se prever marcaçōes exatas e sessões subseqüentes com o mesmo profissional?

Nessa troca inconsciente de experiências dolorosas e difíceis para o terapeuta, é possível que, para se defender de seus conflitos, ele recorra a 
atitudes de onipotência, de arrogância e de autoritarismo. Outras vezes, poderá mesmo usar a Instituição, percebida como instância superegóica, que passará a ser responsabilizada pelas dificuldades pessoais não conhecidas ou assumidas. Como bem já assinalou Julio de Melo, (4) criam-se verdadeiras situaçōes de conluio anônimo entre os membros da equipe hospitalar, no rodízio por vezes desnecessário entre os terapeutas. A psicanálise, mais uma vez, nos ajudará a compreender as dificuldades existentes nos interrelacionamentos terapeuta/paciente. Se dispomos de uma teoria que nos ajuda a entender nossos núcleos conflitivos, por que não aproveitarmos esses conhecimentos e tentarmos melhorar nossos atendimentos psiquiátricos? Não estamos, com isso, levantando a bandeira da psicanálise como a teoria que tudo resolve e a tudo completa. Apenas insistimos no que podemos conseguir incluindo os seus conceitos, o que acreditamos nos ajudaria a capacitar uma melhor qualidade de atendimento. Como escreve Regina Herzog (S): "ć importante deixar bem marcado que não se trata de um movimento unilateral, a medicina tentando apropriar-se do discurso psicanalítico para preencher uma falta, que é estruturante, pela integração deste discurso ao seu. Tambén não se trata absolutamente de integração, noção que remete à idéia de tornar inteiro, completar, beneficiando-se de conceitos de fora de seu campo. Se fosse este o caso, teríamos que, forçosamente, concluir que a influência da psicanálise na medicina se dá pela demanda desta com um objetivo específico, o de completude. Trata-se, sim, de uma inserção, que remete à idéia de introduzir, incluir $e$ a qual a psicanálise responde positivamente".

Seria interessante parar um pouco e relembrar o que aconteceu antes do surgimento da psicanálise, recuando um pouco na história da psiquiatria.

Retornaremos a alguns pontos do muito que já se escreveu sobre a história da psiquiatria. Desde a idade clássica, a burguesia dominante, não querendo se sentir molestada pelos camponeses desempregados que invadiam a cidade, ou mesmo pelos vadios, vagabundos e loucos, começou a usar pretexto para trancafiá-los à guisa de defesa da sociedade. Locais se- gregados, sem nenhuma vocação médica, passaram a constituir a base do que seriam, posteriormente, os manicômios. Os loucos substituíram os leprosos na política de segregacionamento. Inicialmente uma questão mais de ordem econômica e política justificava esse enclausuramento. Pressionada pela necessidade de afirmação e poder da classe burguesa, no nosso mundo ocidental, a psiquiatria vai nascer para proteger a sociedade contra a "loucura".

Por volta de 1656, o Hospital Geral de Paris chegou a abrigar 6.000 pessoas entre mendigos, vagabundos, loucos e desempregados, sendo assim - $1^{\circ}$ marco do início desse processo de reclusão arbitrária.

No século XIX, como bem observa Foucault (6) vai ser "entre os muros do internamento que Pinel e a psiquatria vão encontrar os loucos". Neste contexto, os asilos mais se assemelhavam a uma instituição policial.

Por serem considerados casos sociais, falsas imagens foram sendo associadas a estas criaturas ou, melhor dito, à loucura estigmatizada pela culpa, falta e castigo (7)

Progressivamente, as funçōes carcerárias foram substituídas por funções médicas, passando a loucura a ser ocupada pela psiquiatria que, mesmo sem querer, transformou o doente mental numa pessoa sem direjtos, privada de todo valor social. $O$ seu dizer valia menos do que o seu agir; mais considerado un objeto e não uma pessoa, o louco ia sendo enquadrado numa realidade nosográfica segundo o esquema tradicional: diagnóstico - prognóstico - terapêutica. A intenção do psiquiatra era constatar a doença sem considerar a pessoa. Não é sem sentido dizer que a linguagem da psiquiatria tornou-se no século XIX o "monólogo da razão sobre a loucura", o "asilo encadeando no louco o homem e a sua verdade" (8).

O doente não sendo valorizado no seu discurso deixa-se perder no interrogatório que lhe é imposto, deixando-se também que se escape sua história pessoal.

Esta situação absurda dos hospitais começam a incomodar provocando críticas das estruturas asilares que pretendiam a modificação destes locais de encarceramento da loucura. E é então, neste momento, no século XIX, que vão surgir as idéias inova- doras de Freud, com seus novos enfoques sobre a compreensão da mente humana. Freud com a noção do inconsciente dinâmico vai contribuir decisivamente para a abertura de muitos questionamentos e recolocar a compreensão da loucura.

São as palavras de J. Birman (9): "a psicanálise realizou a sua emergência no campo histórico por uma rutura com o saber psiquíatrico e com o saber médico, constituindo um saber sobre a loucura que questionava simultaneamente o estatuto de ambos para decifrarem a sua verdade. A loucura passa a ser investigada como verdade, seja porque lhe c devolvido o poder de falar, seja porque um discurso teórico consegue articular a comprensão de sua insensatez .

A luta não foi pequena. Freud encontrou inúmeras resistências por parte da psiquiatria conservadora, com obstáculos à sua expansão. Aceitar as noçöes do incosciente e as novas idéias sobre a teoria da sexualidade significava romper com a idéia de causalidade orgânica sobre a qual a psiquiatria se estabelecera. A psicanálise abalava as idéias até então estabelecidas.

Os trabalhos de Freud sobre a histeria vão criar um ponto marcante na psiquiatria, com a noção de corpo simbólico, suporte desta loucura. As observaçōes não ficariam mais restritivas a um corpo anátomo-patológico, até então ponto básico para explicação de todas as enfermidades. Surgia um corpo representado que unifica a totalidade significativa de suas manifestaçöes somáticas" (10).

As grandes contribuições da psicanálise com uma nova compreensão da etiologia das neuroses, a compreensāo dos sonhos, dos atos falhos e lapsos alargaram os conceitos até então vigentes, possibilitando uma nova maneira de avaliar o doente mental. Castel (11) vai afirmar que "a psicanálise foi o operador principal do deslocamento das modalidades de intervenção psiquiátrica".

Novas portas se abriram no conhecimento da pessoa; o relacionamento terapêutico passou a ser melhor entendido, com uma maior valorização dada à escuta. $\mathrm{O}$ discurso do paciente passava a ter sentido. A escuta apreendida através do silêncio, das lacunas, procurava resgatar todo o sentido que, às vezes, os sintomas somente eram insuficientes para trans- 
mitir o que se passava na interioridade daquele ser.

A doença passou a ser entendida como a expressão de um conflito devido à impossibilidade de realização do prazer. A doença mental assim avaliada passou a ser uma verdade a ser decifrada.

A descoberta do inconsciente aumentou as possibilidades de compreensão do conflito psíquico. $O$ paciente com a sua história melhor compreendida passava também a sentir maior compreensão e segurança no atendimento. Vale salientar como é importante a colaboração do paciente no estabelecimento do processo terapêtico. $O$ paciente, agora, participa do tratamento se assim o quiser. A terapia surge como o lugar de trabalhar o desejo do cliente, não mais obrigado a responder interrogatórios. Ele passa a investigar a sua própria verdade.

A valorização dada à escuta, à biografia do paciente fazia com que este nảo mais se sentisse vasculhado em busca de sintomas, num interrogatório policialesco que servia para enquadrá-lo numa categoria de doença mental.

Com o novo sentido dado à biografia da pessoa, a doença passou a fazer parte da história. Todos os comportamentos e acontecimentos do homem passaram a ter um sentido e uma significação.

Winnicott dirá posteriormente que a "contribuição mais importante da psicanálise, à psiquiatria e à classificação psiquiátrica é a supressão da velha idéia de entidades nosológicas" (12).

A psicanálise vai questionar o "estatuto da enfermidade da loucura e estabelecendo uma rutura no plano do saber" (13).

A dimensāo maior dada à escuta calcada na relação transferencial, será fundamental para o enriquecimento da tarefa psiquiátrica. Recordemos também que, já a partir do século $X X$, a medicina começou a se interessar mais pelo doente do que pela doença. A "ordem do organismo", acrescentava-se uma outra ordem, a "da biografia" (14), o que levará à compreensão da pessoa $\mathrm{cm}$ seus dois aspectos da vida humana. "A doença tem um sentido além de uma causa para quem a sofre, que se insere na trama de uma história, marcada nos seus vários registros libidinais" (14).
Marcantes foram também as novas contribuições que se acrescentaram através dos sucessores de Freud. A grande contribuiçâo de Melanie Klein na compreensão dos processos precoces do desenvolvimento da criança"; Winnicott com sua abordagem dos casos difíceis, dos "bordelines" e dos distúrbios de caráter, sem esquecer o muito que trouxe para o novo enfoque na compreensảo e etiologia da psicose; Masud Khan continuando a aprofundar as contribujções de Winnicott; Lacan, o teórico da psicanálise que profundamente marcou, pelo seu ensino, o movimento psicanalítico francês; sem esquecer o grande trabalho desenvolvido pela psicossomática.

Com este histórico acreditamos que esclarecemos o porquê do nosso objetivo de trabalho no HC. Aproveitar o possível do referencial psicanalítico para tentar melhor atender a uma demanda sempre crescente de uma população quase sempre de baixa renda.

Avaliaçöes sucessivas com nossos grupos de supervisionandos, e conosco mesmo, nos encorajam a prosseguir. Algumas vezes, entretanto, questões surgiram sobre a validade desse nosso esforço. Com esse modo de proceder teríamos certeza da cura dos pacientes? Essa tentativa de estabelecer um "setting" estruturante para os pacientes, com o esforço de melhorar a escuta de suas biografias, corresponderia ao desejo oculto numa procura de consulta médica? E, o que $e$ a cura? Confessamos não ter respostas. Entretanto, ainda que nosso trabalho feito nos moldes atuais no HC não leve a cura de determinadas doenças, que se instalam dentro de um contexto sócio-cultural tão abrangente, cuja complexidade nos torna incapazes de ajudar, ainda assim acreditamos que estaríamos contribuindo para que o paciente descubra seu posicionamento no mundo, se apercebendo dos seus limites, seus direitos e seus deveres. Ser respeitado, ser ouvido em suas queixas, às vezes longas ou desinteressantes, é qualquer coisa que nos faz pensar em respeito ao outro. Acreditamos que, se juntos nos esforçássemos, terapeuta e paciente, iríamos aumentando nosso espaço de reinvindicaçōes, de direitos e deveres, sem receiarmos opressöes maiores. Estaríamos tentando para que o paciente adquirisse, também, seus direi- tos de cidadania que, em algumas vezes, quem sabe, poderia representar a sua cura.

Mesmo embalados por estas propostas de esperanca, paramos para voltar a nos questionar. Será mesmo que as noçōes descobertas por Freud contribuíram suficientemente para alargar os nossos horizontes e os da psiquiatria? Não será que ainda teremos muito a fazer? Como entender que os asilos carcerários do século passado se modificaram, se ainda existem hospitais de grande porte que, de algum modo, trancafiam os nossos pacientes, acentuando mais ainda a sua dor? Que resistências tão fortes são essas que nem as contribuicões psicanalíticas conseguiram modificar? São questōes que nos ficam. Fica também a curiosidade em saber como faremos e como melhor utilizaremos o grande legado de Freud e seus sucessores.

Finalizamos com uma citação de Mannoni, M. (15): "não é o psiquiatra ou a sociedade que criam a loucuca, mas, eles são responsáveis pela maneira com que a loucura se cristaliza nos asilos".

(3) - Participa deste grupo de supervisāo, como co-supervisor o Dr. Tácito Augusto Medeiros.

(4) - J. Mello Filho. Concep̧ão psicossomática: tisāo atual, Rio, Tempo Brasileiro, 1979 , p. 92

(5) - R. Herzog. A questāo da influència da psicanálise na medicina, In: Efeito Psi, Rio, Campus, 1988, pg. 61.

(6) - Foucault, M. Historie de la folie. Paris, 10/18, 1961, 0.55

(7) - M. Fleming. Ideologias e práticas psiquiátricas. Porto, Afrontamento, 1976, p. I6

(8) - Foucault, M, in Maus Mannoni, O psiquiatra, seu "louco" e a psicanálise.

Rio, Zahar, 1971, p . S8.

(9) - Birman, J. Demanda psiquiátrica e saber psiguiátrico, In: Sociedade e doença mental, Campus, Rio, 1978 , p. 206.

(10) - Birman J. - Obra citada.

(11) - Castel, R, citado por Fleming M., obre citada, $\mathrm{p} .78$.

(12) - Winnicott. D. O ambiente e os processos de maturaçāo. Porto Alegre, Artes Médicas, 1982, p. 114

(13) - Birman, J. obra citada, p. 2 I 1

(14) - Birman, J. citado por Herzog, R., obra citada, p. $5^{-}$

(15) - Mannoni, M. obra cirada, p . 33 CASTEL, R.: A psicanálise no campo das técnicas médico-psicoterápicas em Psicanálise e sociedade, Belo Horizonte, Interlivros, 1977.

CLAVREUL, J.:A ardem médica. Poder $e$ importancia do discterso médico, Sāo Paulo, Brasiliense. 1983. 